\title{
DIMENSI METRIK PADA GRAF BUKU GANDA
}

(METRIC DIMENSION ON DOUBLE BOOK GRAPHS)

\author{
Nur Ilmayasinta ${ }^{1}$ \\ 1Universitas Islam Lamongan, nurilma@unisla.ac.id
}

\begin{abstract}
Abstrak. Misalkan $G$ graf terhubung dengan $V(G)$ himpunan simpul $v$ pada graf $G$, himpunan sisi $E(G)$ dan $S \subseteq V(G)$ dengan simpul $v \in V(G)$, jarak antara $v$ dan $S$ adalah $d(v, S)=$ $\min \{d(v, x) \mid x \in S\}$. Untuk himpunan terurut $W=$ $\left\{w_{1}, w_{2}, \ldots, w_{k}\right\}$ dari simpul-simpul dalam $G$ dan $v$ pada $V(G)$, representasi dari $v$ terhadap $W$ adalah $k$-vektor, dengan $r(v \mid W)=\left(d\left(v, w_{1}\right), d\left(v, w_{2}\right), \ldots, d\left(v, w_{k}\right)\right)$ untuk setiap $v$ pada $V(G)$ berbeda, maka $W$ disebut himpunan pembeda dari $G$. Kardinalitas minimum dari suatu himpunan pembeda disebut dimensi metrik dari $G$ dinotasikan dengan $\operatorname{dim}(G)$. Pada penelitian ini dilakukan analisis dimensi metrik terhadap graf buku ganda $\left(2 B_{n}\right)$ dan graf buku ganda $\left(2 B_{n, m}\right)$. Dari analisis yang telah dilakukan diperoleh dimensi metrik graf buku ganda $\left(2 B_{n}\right)$ adalah $2(n-1)$, sedangkan dimensi metrik graf buku ganda $\left(2 B_{n, m}\right)$ adalah $(n-1)+(m-1)$.
\end{abstract}

Kata kunci: himpunan pembeda, dimensi metrik, graf buku ganda

\begin{abstract}
Let $G$ graph be connected with $V(G)$ set of vertices $v$ on graph $G$, set of sides $E(G)$ and $S \subseteq V(G)$ with $v \in V(G)$, the distance between $v$ and $S$ is $d(v, S)=\min \{d(v, x) \mid x \in S\}$. For $W=$ $\left\{w_{1}, w_{2}, \ldots, w_{k}\right\}$ ordered sets of vertices in connected graph $G$ and $v$ at $V(G)$, the representation of $v$ with $W$ is k-vector, with $r(v \mid W)=$ $\left(d\left(v, w_{1}\right), d\left(v, w_{2}\right), \ldots, d\left(v, w_{k}\right)\right)$ for each $v$ on $V(G)$ is different, then $W$ is called a distinguishing set of $G$. Minimum cardinality of a distinguishing set is called dimension the metric of $G$ is denoted by $\operatorname{dim}(G)$. In this study metric dimension analysis of double book graphs $\left(2 B_{n}\right)$ and double book graphs $\left(2 B_{n, m}\right)$ was carried out. From the analysis that has been done, the metric dimension of the double book graph $\left(2 B_{n}\right)$ is obtained $2(n-1)$, while the metric dimension of the double book graph $\left(2 B_{n, m}\right)$ is $(n-1)+(m-1)$.
\end{abstract}

Keywords: distinguishing set, metric dimension, double book graphs 


\section{PENDAHULUAN}

Teori graf pertama kali diperkenalkan oleh Leonhard Euler pada tahun 1736 ketika mencoba membuktikan kemungkinan untuk melewati empat daerah yang terhubung dengan tujuh jembatan di atas sungai Pregel di Konisberg, Rusia dalam sekali waktu. Masalah jembatan Konisberg tersebut dapat dinyatakan dalam graf dengan menentukan keempat daerah tersebut sebagai titik dan ketujuh jembatan sebagai sisi yang menghubungkan pasangan titik yang sesuai. Salah satu topik dalam teori graf adalah dimensi metrik pada graf.

Dimensi metrik pertama kali dikenalkan oleh Harary dan Melter pada tahun 1966, kajian tentang dimensi metrik menjadi sebuah complate problem artinya tidak mudah untuk mendapatkan dimensi metrik dari suatu graf bentuk tertentu. Oleh karenanya untuk mendapatkan dimensi metrik bentuk graf tertentu ataupun kelas tertentu dilakukan analisis dari subkelas terlebih dahulu agar lebih mudah mencari dimensi metrik dari graf secara umum. Untuk simpul $u$ dan $v$ dalam graf terhubung $G$, jarak $d(u, v)$ adalah panjang dari lintasan terpendek antara $u$ dan $v$ pada $G$. Untuk himpunan terurut $W=\left\{w_{1}, w_{2}, \ldots, w_{k}\right\}$ dari simpul-simpul dalam graf terhubung $G$ dan simpul $v$ pada $G$, adalah vektor- $k$ (pasangan $k$ tuple), $\quad r(v \mid W)=\left(d\left(v, w_{1}\right), d\left(v, w_{2}\right), \ldots, d\left(v, w_{k}\right)\right) \quad$ menunjukkan representasi dari $v$ pada $W$. Himpunan $W$ dinamakan himpunan pembeda (resolving set) $G$ jika simpul-simpul $G$ mempunyai representasi berbeda. Kardinalitas minimum dari himpunan pembeda disebut dimensi metrik dari $G$, dan dinotasikan dengan $\operatorname{dim}(G)$ (R, Rahadjeng, Si, \& Si, n.d.).

Sebuah graf lintasan $P_{n}$ adalah graf yang terdiri dari satu lintasan. Graf bintang (Star) $S_{n}$ merupakan pohon pada $n$ titik yang mempunyai satu titik berderajat $n-1$ dan $n-1$ titik berderajat satu. Graf Star isomorfik dengan graf Bipartit lengkap $K_{(1, n-1)}$. Banyak sisi pada suatu graf bintang yang terdiri dari $n$ buah titik adalah $n-1$. Untuk $n \geq 3$, graf buku (book graph) $B_{n}$ adalah graf hasil kali kartesius $S_{n+1} \times P_{2}$, dimana $S_{n+1}$ adalah graf bintang dengan $n+1$ titik dan $P_{2}$ adalah graf lintasan dengan 2 titik. Banyak titik pada graf buku $B_{n}$ adalah $2(n+1)$ dan banyak sisi adalah $(3 n+1)$ (Tikasari et al., n.d.).

Sebelumnya, penelitian tentang dimensi metrik sudah banyak dilakukan, salah satunya oleh Annga B D., dan Darmaji, yang melakukan penelitian tentang dimensi metrik graf pohon bentuk tertentu[4]. Penelitian tentang graf buku pernah dilakukan oleh Sri Kuntari dkk, yang menunjukkan bahwa digraf eksentrik dari graf buku adalah digraf $S_{n} \cup$ $\left(K_{n, n}-M\right) \cup S_{n}$, dengan $S_{n}$ graf bintang, $K_{n, n}$ graf bipartit lengkap dan $M$ matching dari $K_{n, n}$ (Kuntari \& Sudibyo, 2011).

Sejauh ini belum dilakukan penelitian dimensi metrik pada graf buku ganda $2 B_{n}$, oleh karena itu pada penelitian ini akan dilakukan analisa dimensi metrik pada graf buku ganda $2 B_{n}$. 


\section{METODE}

a. Graf

Graf adalah pasangan himpunan $(V, E)$ dimana $V$ adalah himpunan tidak kosong dari titik dan $E$ adalah himpunan tidak kosong yang menghubungkan sepasang titik pada suatu graf. Misalnya $V=$ $\left\{v_{1}, v_{2}, \ldots, v_{n}\right\} \quad$ dan $E=\left\{e_{1}, e_{2}, \ldots, e_{n}\right\}$ atau $E=$ $\left\{\left(v_{1}, v_{2}\right),\left(v_{2}, v_{2}\right), \ldots,\left(v_{n-1}, v_{n}\right)\right\}$ dimana $E=\left\{v_{i}, v_{j}\right\}$ yang artinya sisi yang menghubungkan titik $v_{i}$ dan $v_{j}$.(Roda \& Javaid, n.d.)

b. Graf Komplit

Graf komplit dengan $n$ titik, dilambangkan dengan $K_{n}$ adalah graf sederhana dengan $n$ titik dan setiap dua titik berhubungan langsung.( $R$ et al., n.d.)

c. Graf Lintasan

Graf lintasan yang dinotasikan dengan $P_{n}$ adalah graf yang mempunyai tepat satu lintasan dengan $n$ titik dan panjang $n-1$. (R et al., n.d.)

d. Graf Bipartit

Graf $G$ disebut graf bipartit jika himpunan titik pada graf $G$ dapat dipartisi menjadi dua himpunan bagian $A$ dan $B$ sedemikian hingga setiap sisi dari graf $G$ menghubungkan sebuah titik di $A$ dan sebuah titik di $B$. Apabila setiap titik di $A$ berhubungan langsung dengan setiap titik di $B$, maka $G$ disebut graf bipartit komplit yang dinotasikan dengan $K_{s, t}$ dimana $s$ banyak titik pada $A$ dan $t$ banyak titik pada $B$.(R et al., n.d.)

e. Graf Bintang

Graf bintang yang dinotasikan dengan $K_{1, n-1}$ adalah graf bipartit komplit dengan $n$ titik. Graf $K_{1, n-1}$ mempunyai satu titik berderajat $n-1$ yang disebut titik pusat dan $n-1$ titik berderajat satu yang disebut daun.(R et al., n.d.)

f. Graf buku

$B_{n}$ dimana $n \geq 3$ merupakan graf cartesian product $S_{n+1} \times P_{2}$ dengan $S_{n}$ adalah graf bintang. Dimana graf sendiri isomorfik dengan graf bipartit lengkap $S_{n} \cong K_{1, n-1}$. (Kuntari \& Sudibyo, 2011)

g. Graf buku ganda

$2 B_{n}$ dimana $n \geq 3$ merupakan hasil amalgamasi sisi $P_{2}(u, v)$ dimana $u, v \notin K_{1}$. Untuk Graf buku ganda $2 B_{n, m}$ dimana $n, m \geq 3$ merupakan hasil amalgamasi sisi $P_{2}(u, v)$ dimana $u, v \notin K_{1}$.

h. Jarak

Jarak (distance) antara simpul $u$ dan $v$ pada graf $G$, dinotasikan dengan $d(u, v)$ adalah panjang lintasan terpendek antara $u$ dan $v$ pada graf $G$ (Permana \& Darmaji, 2012).

i. Dimensi Metrik

Slater dan Imran dkk (2012) menyebutkan suatu himpunan dengan sebutan locating set yang sering dikenal dengan himpunan pembeda (resolving set). Diberikan sebuah graf terhubung $G$. Misalkan dua 
simpul $u$ dan $v$ adalah simpul-simpul dari graf terhubung $G$. Jarak antara simpul $u$ dan $v$ didenisikan sebagai lintasan terpendek dari simpul $u$ ke $v$ di $G$ dan dinotasikan $d(u, v)$. Jika diberikan suatu himpunan terurut $W=\left\{w_{1}, w_{2}, w_{3}, \ldots, w_{k}\right\} \subseteq V(G)$ dari simpul-simpul dalam graf terhubung $G$ dan simpul $v$ di $V(G)$, maka representasi dari simpul $v$ terhadap $W$ adalah $r(v \mid W)=$ $\left(d\left(v, w_{1}\right), d\left(v, w_{2}\right), d\left(v, w_{3}\right), \ldots, d\left(v, w_{k}\right)\right)$. Jika $r(v \mid W)$ untuk setiap simpul $v \in V(G)$ berbeda, maka $W$ disebut sebagai himpunan pembeda dari $V(G)$. Himpunan pembeda dengan kardinalitas minimum disebut himpunan pembeda minimum. Kardinalitas dari himpunan pembeda minimum disebut dimensi metrik dari graf $G$ yang dinotasikan $\operatorname{dim}(G)$ (Alfarisi et al., 2017). Permana dan Darmaji (2012) memberikan Lemma 2.1 untuk menentukan setiap anggota himpunan berbeda memiliki representasi yang berbeda.(Permana \& Darmaji, 2012)

Lemma 1. Untuk setiap simpul $u$ anggota himpunan pembeda $Z$ pasti memiliki representasi yang berbeda terhadap $Z$.

Bukti:

Misalkan terdapat sebuah graf terhubung $G$ dengan himpunan simpul $V(G)=\left\{u_{1}, u_{2}, \ldots, u_{n}\right\}$ dan himpunan pembeda $Z=\left\{u_{1}, u_{2}, \ldots, u_{n}\right\}$ jika dilakukan analisis jarak setiap simpul anggota pada himpunan pembeda diperoleh:

$$
\begin{aligned}
& r\left(u_{1} \mid Z\right)=\left(0, p_{2}, p_{3}, \ldots, p_{n}\right) \\
& r\left(u_{2} \mid Z\right)=\left(p_{1}, 0, p_{3}, \ldots, p_{n}\right) \\
& r\left(u_{3} \mid Z\right)=\left(p_{1}, p_{2}, 0, \ldots, p_{n}\right)
\end{aligned}
$$

seterusnya sampai $r\left(u_{n} \mid Z\right)=\left(p_{1}, p_{2}, p_{3}, \ldots, p_{n}\right)$ memiliki representasi yang berbeda terhadap $Z$.

Selanjutnya, definisi tentang dimensi metrik diberikan oleh Harary dan Melter.

Definisi 1. Subset $W$ adalah set penyelesaian jika $r(v \mid W)$ untuk setiap dua simpul $G$ memiliki representasi yang berbeda. Set penyelesaian kardinalitas minimum untuk graf $G$ disebut set penyelesaian minimum atau basis untuk $G$. Dimensi metrik $G$, dilambangkan dengan $\operatorname{dim}(G)$, adalah basis untuk $G$.

\section{HASIL DAN PEMBAHASAN}

Teorema 1. Graf buku ganda $2 B_{n}$ dengan $n \geq 3$ memiliki dimensi metrik $\operatorname{dim}\left(2 B_{n}\right)=2(n-1)$.

Bukti:

Dilakukan beberapa percobaan, kemudian dari beberapa percobaan tersebut diperoleh supremum dari dimensi metrik sebagai berikut:

untuk $n=3$ dimensi metriknya adalah 4 , dan diberikan gambar untuk $2 B_{3}$ pada Figure 1 . Untuk menemukan batas atas dimensi $2 B_{3}$ dilakukan

24 Jurnal Pendidikan Matematika dan Matematika Vol. I No. 01 Februari 2019 
konstruksi, misalkan diambil himpunan pembeda $W=\left\{v_{1}, v_{2}, v_{5}, v_{7}\right\}$, maka diperoleh representasi terhadap $W$ :

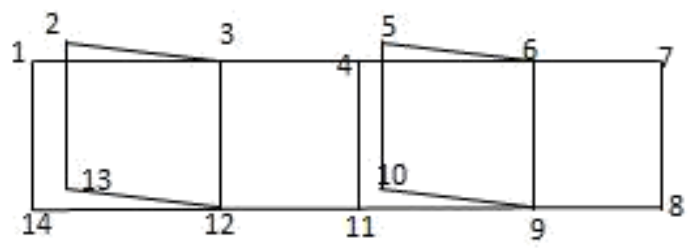

Figure 1: $2 \mathrm{~B}_{3}$

$$
\begin{aligned}
& r\left(v_{1} \mid W\right)=(0,2,4,4) \\
& r\left(v_{2} \mid W\right)=(2,0,4,4) \\
& r\left(v_{3} \mid W\right)=(1,1,3,3) \\
& r\left(v_{4} \mid W\right)=(2,2,2,2) \\
& r\left(v_{5} \mid W\right)=(4,4,0,2) \\
& r\left(v_{6} \mid W\right)=(3,3,1,1) \\
& r\left(v_{7} \mid W\right)=(4,4,2,0) \\
& r\left(v_{8} \mid W\right)=(5,5,3,1) \\
& r\left(v_{9} \mid W\right)=(4,4,2,2) \\
& r\left(v_{10} \mid W\right)=(5,5,3,1) \\
& r\left(v_{11} \mid W\right)=(3,3,3,3) \\
& r\left(v_{12} \mid W\right)=(2,2,4,4) \\
& r\left(v_{13} \mid W\right)=(3,1,5,5) \\
& r\left(v_{14} \mid W\right)=(1,3,5,5)
\end{aligned}
$$

sehingga didapat bahwa dimensi metrik dari graf buku ganda $2 B_{3}$ adalah 4. Selanjutnya didapat bahwa graf buku ganda $2 B_{n}$ :

untuk $n=3$ dimensi metriknya adalah 4

untuk $n=4$ dimensi metriknya adalah 6

untuk $n=5$ dimensi metriknya adalah 8

untuk $n=6$ dimensi metriknya adalah 10

untuk $n=7$ dimensi metriknya adalah 12,

sehingga dari 6 percobaan diatas diperoleh supremum dari dimensi metrik adalah $2(n-1)$, sehingga infimum $\leq \operatorname{dim}\left(2 B_{n}\right) \leq 2(n-1)$.

Selanjutnya akan ditunjukkan infimumnya adalah $2(n-1)$ sehingga $\operatorname{dim}\left(2 B_{n}\right)=2(n-1)$. Andaikan infimum dari dimensi metrik $2 B_{n}$ adalah $2 n-3$, ambil sebarang bilangan pembeda sebanyak $2 n-3$ pada graf $2 B_{n}$, kemudian asumsikan bilangan pembeda yang diambil adalah yang memiliki diameter terbesar yaitu pada simpul ujung tiap lembar graf $2 B_{n}$, untuk simpul dengan diameter terjauh diujung graf $2 B_{n}$ maka pasti himpunan pembedanya berbeda sehingga banyaknya menjadi $2(n-1)$, dengan mengambil bilangan pembeda sebanyak $2 n-3$ dan dimensi metrik 2(n-1) maka sesuai prinsip rumah merpati (php) maka pasti ada setidaknya 2 himpunan pembeda yang sama (kontradiksi) dengan by way of contradictions diatas minimal dibutuhkan sebanyak $2(n-1)$ bilangan 
pembeda agar semua himpunan pembeda graf $2 B_{n}$ bisa berbeda untuk setiap simpulnya.

Jadi infimum dimensi metrik graf $2 B_{n}$ adalah $2(n-1)$, sehingga $2(n-1) \leq \operatorname{dim}\left(2 B_{n}\right) \leq 2(n-1)$.

$\therefore \operatorname{dim} G\left(2 B_{n}\right)$ adalah $2(n-1)$.

Teorema 2. Graf buku ganda $2 B_{n, m}$ dengan $n, m \geq 3$ memiliki dimensi metrik $\operatorname{dim}\left(2 B_{n, m}\right)=(n-1)+(m-1)$.

Bukti:

dari beberapa percobaan diperoleh supremum dari dimensi metrik sebagai berikut:

untuk $n=3$ dan $m=4$ dimensi metriknya adalah 5

untuk $n=3$ dan $m=5$ dimensi metriknya adalah 6

untuk $n=4$ dan $m=3$ dimensi metriknya adalah 5

untuk $n=4$ dan $m=5$ dimensi metriknya adalah 7

untuk $n=5$ dan $m=3$ dimensi metriknya adalah 6 ,

dari 7 percobaan diatas diperoleh supremum dari dimensi metrik graf $2 B_{n, m}$ adalah $(n-1)+(m-1)$.

Maka, infimum $\leq \operatorname{dim}\left(2 B_{n, m}\right) \leq(n-1)+(m-1)$.

Akan ditunjukkan infimumnya adalah $(n-1)+(m-1)$ sehingga $\operatorname{dim}\left(2 B_{n, m}\right)=2 n$.

Andaikan infimum dari dimensi metrik $2 B_{n, m}$ adalah $(n-1)+(m-1)-$ 1 , ambil sebarang bilangan pembeda sebanyak $(n-1)+(m-1)-1$ pada graf $2 B_{n, m}$, kemudian asumsikan bilangan pembeda yang diambil adalah yang memiliki diameter terbesar yaitu pada simpul ujung tiap lembar graf $2 B_{n, m}$, untuk simpul dengan diameter terjauh diujung graf $2 B_{n, m}$ maka pasti himpunan pembedanya berbeda sehingga banyaknya menjadi $(n-$ $1)+(m-1)$, dengan mengambil bilangan pembeda sebanyak $(n-1)+$ $(m-1)-1$ dan dimensi metrik $(n-1)+(m-1)$ maka sesuai prinsip rumah merpati (php) maka pasti ada setidaknya 2 himpunan pembeda yang sama (kontradiksi) dengan by way of contradictions diatas minimal dibutuhkan sebanyak $(n-1)+(m-1)$ bilangan pembeda agar semua himpunan pembeda graf $2 B_{n, m}$ bisa berbeda untuk setiap simpulnya.

Jadi infimum dimensi metrik graf $2 B_{n, m}$ adalan $(n-1)+(m-1)$, sehingga $(n-1)+(m-1) \leq \operatorname{dim}\left(2 B_{n, m}\right) \leq(n-1)+(m-1)$.

$\therefore \operatorname{dim} G\left(2 B_{n, m}\right)$ adalah $(n-1)+(m-1)$.

\section{KESIMPULAN DAN SARAN}

Dari hasil penelitian yang dilakukan, dapat disimpulkan bahwa:

1. Dimensi metrik dari graf buku ganda $2 B_{n}$ adalah $2(n-1)$.

2. Dimensi metrik dari graf buku ganda $2 B_{n, m}$ adalah $(n-1)+(m-1)$.

\section{DAFTAR PUSTAKA}


Alfarisi, R., Magister, P., Matematika, J., Matematika, F., Ilmu, D. A. N., \& Alam, P. (2017). Dimensi partisi dan dimensi partisi bintang graf hasil operasi comb dua graf terhubung.

Kuntari, S., \& Sudibyo, N. (2011). Digraf eksentrik dari graf buku, 223-226.

Permana, A. B., \& Darmaji. (2012). Dimensi metrik graf pohon bentuk tertentu. Jurnal Teknik Pomits, 1(1), 1-4.

R, S. E., Rahadjeng, B., Si, S., \& Si, M. (n.d.). Dimensi Metrik pada Graf Lintasan, Graf Komplit, Graf Sikel, Graf Bintang dan Graf Bipartit Komplit, 1-6.

Roda, G., \& Javaid, I. (n.d.). Dimensi Metrik dan Dimensi Partisi dari Famili Graf Tangga, (49), 105-112.

Tikasari, A., Rahadjeng, B., Si, S., Si, M., Surabaya, U. N., \& Surabaya, U. N. (n.d.). PELABELAN SISI AJAIB DAN SISI AJAIB SUPER PADA GRAF KIPAS , GRAF TANGGA , GRAF PRISMA , GRAF LINTASAN , GRAF SIKEL , DAN GRAF BUKU, 1-5. 